\author{
Nataliya S. Belinskaya* \\ Emiliya D. Ivanchina \\ Igor M. Dolganov
}

Natalia E. Belozertseva

Daria A. Afanaseva

\section{Computer Modeling System of the Industrial Diesel Fuel Catalytic Dewaxing Process}

An unsteady mathematical model and a computer modeling system of the diesel fuel catalytic dewaxing process (mild hydrocracking) were developed. The modeling system allows for calculating the optimal technological mode to produce lowfreezing diesel fuel with the required cold filter plugging point taking into account the feedstock composition and catalyst activity. The modeling system consists of the main blocks: database, knowledge base, unsteady mathematical model of the diesel fuel catalytic dewaxing process, and application program package. Using the developed computer modeling system, the influence of the feedstock composition and flow rate as well as of the catalyst activity on the cold filter plugging point and the yield of diesel fuel is demonstrated.

Keywords: Cold filter plugging points, Computer modeling systems, Diesel fuel, Hydroprocessing, Mild hydrocracking

Received: September 22, 2019; revised: September 10, 2020; accepted: October 21, 2020

DOI: 10.1002/ceat.201900516

\section{Introduction}

In recent decades, there has been a tendency to depletion of the light oil reserves. As a result, the increase in oil production is provided by heavy, hardly recoverable oil $[1,2]$. Heavy oil fractions contain a significant amount of long-chain unbranched paraffins ( $n$-paraffins), which are characterized by high cold filter plugging points $[3,4]$. The demand for diesel fuel, capable of operating at cold climate conditions, is constantly rising due to the development of the economic potential of the regions, which are located in the cold climatic zones, including arctic regions [5]. The process of catalytic dewaxing is aimed at the processing of middle petroleum distillates into components of low-freezing grades of diesel fuel in the hydrogen media at the relatively mild technological parameters [6].

During the operation of industrial catalytic dewaxing units, the deviations from the product specifications arise. This leads to the nonconformance of the cold flow properties to the required ones. The deviations arise due to the following factors: (i) changes in the feedstock composition and flow rate; (ii) coking of the catalyst and, as a consequence, a decrease in the catalyst activity and an increase in the pressure drop in the reactor; (iii) an increase in the residual sulfur content in the hydrotreated fuel due to the coking and poisoning of the catalyst in the hydrotreating reactor, low (not optimal) temperature at the hydrotreating stage, and preceding dewaxing.

Nowadays, to solve multifactorial problems of optimizing oil refining processes under unsteady conditions of the varying feedstock composition and decreasing catalyst activity, physicochemical models are successfully applied [7-9]. The global trend of digitalization in the oil industry, i.e., the introduction of digital solutions and intelligent manufacturing technologies to increase the operational efficiency of enterprises, also makes physicochemical modeling of oil refining processes highly relevant [10]. Mathematical models developed on the physicochemical basis and implemented in the form of the simulation software provide determination of the optimal design, optimal technological mode, which reduces production costs, prolongs the life of expensive catalysts, and reduces the number of emergency situations, quality giveaway, and time of the equipment downtime [11-15].

Several studies are devoted to the development of mathematical models of the hydroconversion processes of diesel fuel production [16-20]. However, there is a lack of software-implemented physicochemical models of the diesel fuel catalytic dewaxing process.

The aim of this work is to develop a computer modeling system for the diesel fuel catalytic dewaxing process, based on the unsteady physicochemical model in order to optimize the process taking into account the feedstock composition and the catalyst activity. 


\section{Diesel Fuel Catalytic Dewaxing Process}

The purpose of the catalytic dewaxing process is hydrocracking of long-chain paraffins, constituting the feedstock, to produce low-freezing diesel fuel. Fig. 1 presents the catalytic dewaxing process flow diagram, which includes: reaction stage (hydrotreating and dewaxing processes), stabilization stage (removal of light hydrocarbons from the hydrogenate after the reactor stage), and rectification stage (separation of the stable hydrogenate into naphtha fraction, diesel fraction, and residue).

The feedstock of the catalytic dewaxing process is a mixture of straight-run diesel fraction and atmospheric gas oil. As a result, diesel fuel components as the target products are obtained, i.e., fraction boiling between $180-340^{\circ} \mathrm{C}$ (low-freezing component) and fraction boiling higher $340^{\circ} \mathrm{C}$. At the industrial plant, a Co-Mo catalyst for hydrotreating and a Nicontaining catalyst for dewaxing are loaded into the reactors.

\section{Computer Modeling System of the Diesel Fuel Catalytic Dewaxing Process}

A computer modeling system is a technically organized manmachine system, which includes a database and a knowledge base about a certain subject area, a physicochemical mathematical model of a process, and an application program package that ensures the functioning of the entire computer modeling system based on collection, storage, and processing of the information. Fig. 2 displays the main blocks of a computer modeling system.

The database contains information or numerical values of the chemical processes and equipment characteristics. These are: design, kinetic, thermodynamic or thermophysical parameters.

The knowledge base of the computer modeling system provides collection, accumulation, and analysis of the information on the functioning of the plant in the form of rules, conclusions, or recommendations.

The mathematical model of the process is a system of equations of material and heat balances. It is developed on the basis of the physical and chemical regularities of the process.

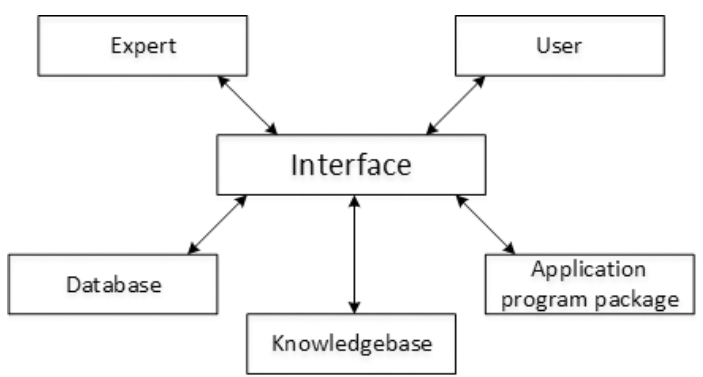

Figure 2. Main blocks of a computer modeling system.

An application program package is a set of procedures for calculating processes and equipment, including programs for calculating typical processes that occur in a chemical-technology system. To provide the interaction between the users and experts with a computer modeling system, an interface is used.

\subsection{Database of the Computer Modeling System}

The database of the developed computer modeling system of the catalytic dewaxing process consists of:

- data on the chemistry of the process and the mechanisms of the occurring reactions;

- thermodynamic characteristics of reactions, i.e., changes in enthalpy, in free Gibbs energy, and in entropy during reactions;

- kinetic parameters of the reactions, i.e., activation energy and preexponential factor in the Arrhenius equation;

- reactor characteristics, i.e., dimensions and design;

- composition and properties of the feedstock, composition of hydrogen-containing gas, and process parameters for a long period of the industrial unit operation.

The main reactions of the catalytic dewaxing process and their thermodynamic and kinetic parameters are summarized in Tab. 1. Thermodynamic parameters of the reactions were calculated using the density functional theory (DFT), model B3LYP, basis 3-21G.

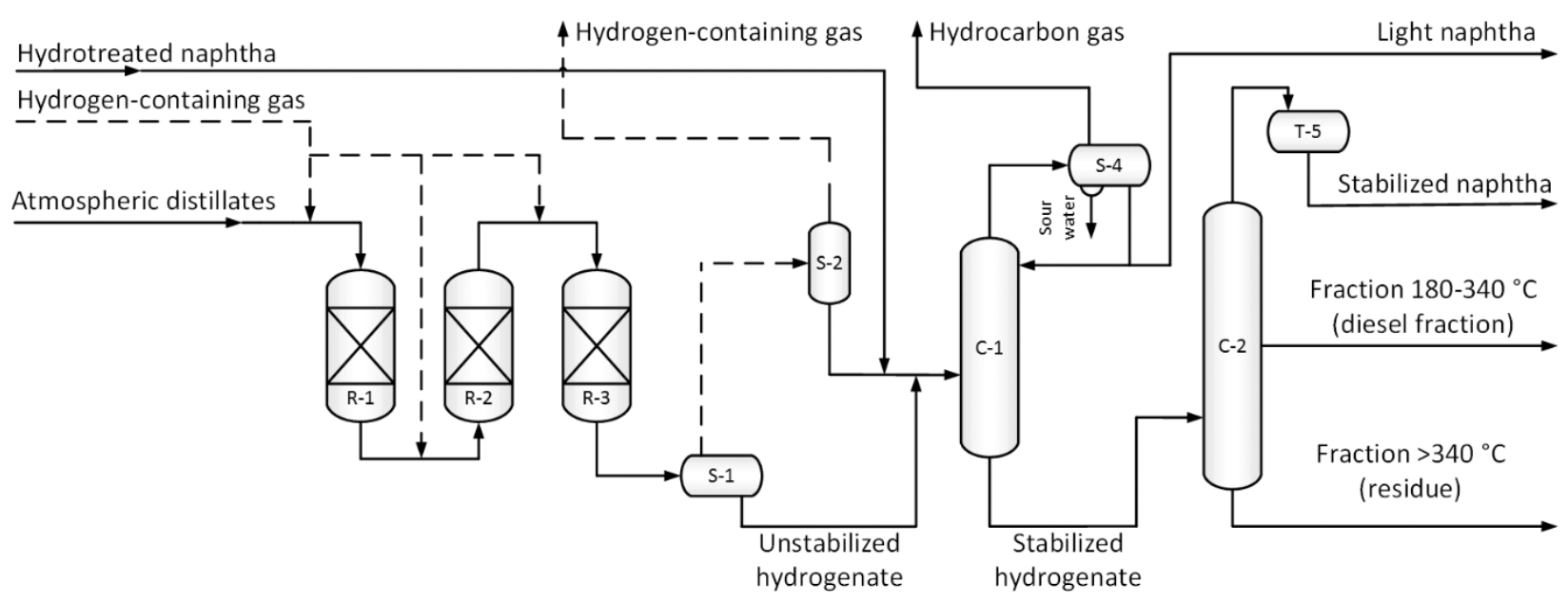

Figure 1. Process flow diagram of the catalytic dewaxing. 
Table 1. Thermodynamic and kinetic parameters of the main reaction of the catalytic dewaxing process.

\begin{tabular}{lccc}
\hline Reaction & $\Delta H\left[\mathrm{~kJ} \mathrm{~mol}^{-1}\right]$ & $\Delta G\left[\mathrm{~kJ} \mathrm{~mol}^{-1}\right]$ & $E_{\mathrm{a}}\left[\mathrm{kJ} \mathrm{mol}{ }^{-1}\right]$ \\
\hline $\begin{array}{l}n \text {-Paraffins } \\
\text { dehydrogenation }\end{array}$ & -144.93 & -77.48 & 110 \\
$\begin{array}{l}\text { Olefins hydrocracking } \\
\text { Olefins isomerization }\end{array}$ & -146.91 & -83.07 & 130 \\
$\begin{array}{l}\text { and hydrogenation } \\
\text { Olefin cyclization }\end{array}$ & -91.22 & -52.77 & 180 \\
$\begin{array}{l}\text { Naphthenes } \\
\text { dehydrogenation }\end{array}$ & -231.33 & -55.31 & 140 \\
Coke formation & -87.90 & -252.90 & 190 \\
$n$-Paraffins cracking & 82.80 & -3.79 & 200 \\
\hline
\end{tabular}

The catalytic dewaxing reactor is a vertical vessel with axial feed input as depicted in Fig. 3. The inert balls of various diameters $(19.0$ and $6.4 \mathrm{~mm})$ are loaded into the lower and middle parts of the reactor. The Co-Mo hydrotreating catalyst with a particle size of $1.2 \mathrm{~mm}$ is loaded at the top of the inert ball layer. The Co-Mo catalyst removes unsaturated compounds or mercaptans, which are formed during the dewaxing reactions. Above the layer of hydrotreating catalyst, a layer of the inert balls with the diameter of $6.4 \mathrm{~mm}$ is loaded, above which the dewaxing catalyst with a particle size of $2.5 \mathrm{~mm}$ is loaded.

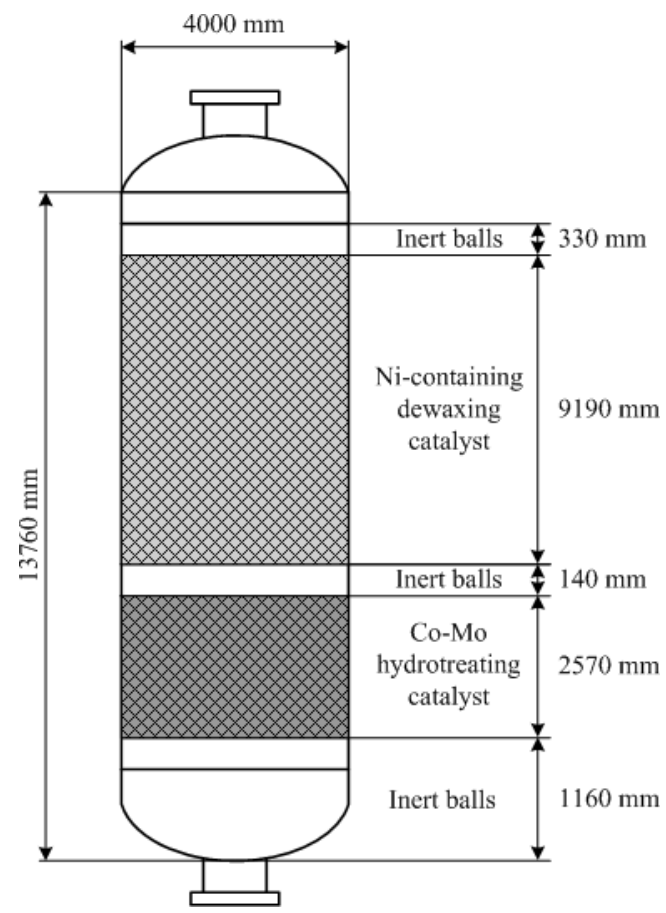

Figure 3. Schematic representation of the catalytic dewaxing reactor.

The height of the reactor is much greater than its diameter. Due to this fact, when developing the model of the reactor, it was assumed that the mode of the ideal displacement is observed in the reactor. An assumption was made about the plug flow in the reactor without longitudinal mixing and uniform distribution of the reaction mass in the direction perpendicular to the flow. The residence time of all particles in the system is equal and it is defined as the ratio of the volume of the system to the volumetric flow rate.

Tab. 2 presents a fragment of the database on the feedstock composition and properties, while Tab. 3 presents technological parameters of the catalytic dewaxing process.

Table 2. Fragment of the database on the feedstock composition and properties. $T_{10 \%}, T_{50 \%}$, and $T_{90 \%}$ are the distillation temperatures of the $10-, 50-$, and $90-\mathrm{vol} \%$ fractions, respectively.

\begin{tabular}{|c|c|c|c|c|}
\hline \multirow{2}{*}{$\begin{array}{l}\text { Sampling } \\
\text { point }\end{array}$} & \multicolumn{3}{|c|}{ Fraction composition } & \multirow{2}{*}{$\begin{aligned} & \text { Density at } 20^{\circ} \mathrm{C} \\
- & {\left[\mathrm{kg} \mathrm{m}^{-3}\right] }\end{aligned}$} \\
\hline & $T_{10 \%}\left[{ }^{\circ} \mathrm{C}\right]$ & $T_{50 \%}\left[{ }^{\circ} \mathrm{C}\right]$ & $T_{90 \%}\left[{ }^{\circ} \mathrm{C}\right]$ & \\
\hline 1 & 239 & 277 & 342 & 849 \\
\hline 2 & 246 & 285 & 349 & 851 \\
\hline 3 & 249 & 290 & 351 & 847 \\
\hline 4 & 248 & 290 & 353 & 848 \\
\hline 5 & 249 & 291 & 355 & 850 \\
\hline
\end{tabular}

\subsection{Knowledge Base of the Computer Modeling System}

The knowledge base of the developed computer modeling system of the catalytic dewaxing process is built on the basis of the technological regulations of the diesel fuel catalytic dewaxing industrial unit. The knowledge base is based on the frame model. The choice of the frame model is justified by the fact that knowledge about the dewaxing process is well structured, the hierarchical system is built from them, and each of the parameters and characteristics of the process are interconnected. In this model, frames are deviations in the operation of the industrial unit, slots are the causes of the deviations and the recommendations for their elimination. The knowledge base of the developed computer modeling system provides collection, accumulation, and analysis of the information on the functioning of the industrial catalytic dewaxing unit.

\subsection{Mathematical Model of the Catalytic Dewaxing Process}

The mathematical model developed on the basis of physicochemical regularities, taking into account the changing feedstock composition and the catalyst deactivation, is a system of differential equations of the material balance by components and the heat balance equation: 
Table 3. Technological parameters of the catalytic dewaxing process.

\begin{tabular}{llllll}
\hline Sampling point & $\begin{array}{l}\text { Feedstock flow rate } \\
{\left[\mathrm{m}^{3} \mathrm{~h}^{-1}\right]}\end{array}$ & $\begin{array}{l}\text { Hydrogen-containing gas } \\
\text { consumption }\left[\mathrm{m}^{3} \mathrm{~h}^{-1}\right]\end{array}$ & $\begin{array}{l}\text { Feedstock temperature } \\
{\left[{ }^{\circ} \mathrm{C}\right]}\end{array}$ & $\begin{array}{l}\text { Hydrogen-containing gas } \\
\text { temperature }\left[{ }^{\circ} \mathrm{C}\right]\end{array}$ & Pressure $[\mathrm{MPa}]$ \\
\hline 1 & 234 & 9589 & 343.7 & 85.0 & 7.5 \\
2 & 247 & 16515 & 346.5 & 85.0 & 7.5 \\
3 & 247 & 19151 & 347.4 & 85.1 & 7.5 \\
4 & 242 & 18059 & 346.9 & 85.2 & 7.5 \\
5 & 242 & 23472 & 349.3 & 85.7 & 7.5 \\
\hline
\end{tabular}

$\left\{\begin{array}{l}G \frac{\partial C_{\mathrm{i}}}{\partial z}+G \frac{\partial C_{\mathrm{i}}}{\partial V}=\sum_{\mathrm{j}=1}^{\mathrm{m}} a_{\mathrm{j}} W_{\mathrm{j}} \\ G \frac{\partial T}{\partial z}+G \frac{\partial T}{\partial V}=\frac{1}{\rho C_{\mathrm{P}}^{C M}} \sum_{\mathrm{j}=1}^{\mathrm{m}} Q_{\mathrm{j}} a_{\mathrm{j}} W_{\mathrm{j}}\end{array}\right.$

The initial conditions are: $z^{1)}=0: C_{\mathrm{i}}=C_{\mathrm{i}, 0} ; T=T_{0} ; V=0: C_{\mathrm{i}}$ $=C_{\mathrm{i}, 0} ; T=T_{0} . z=G t$.

The catalyst activity depends mainly on the rate of coke deposition on the catalyst surface. In the developed model, the catalyst activity is calculated as follows:

$a_{\mathrm{j}}=A_{\mathrm{j}} e^{-\alpha_{\mathrm{j}} \mathrm{C}_{\mathrm{K}}}$

The coke content $\left(C_{\mathrm{K}}\right)$ is determined by solving the system of differential equations (Eq. (1)) in accordance with the mechanism of hydrocarbon conversion [21], taking into account the composition of the processed feedstock and reactions leading to the formation of coke, namely, the reactions of coke formation from aromatic hydrocarbons as aromatic hydrocarbons are most prone to condensation reactions and coke formation.

\subsection{Application Program Package of the Computer Modeling System}

The application program package consists of the following software modules:

- database designed in MS Office Access;

- expert system for diagnosing the causes of deviations in the operation of the industrial catalytic dewaxing unit, developed in the Delphi programming environment;

- main program containing the mathematical model of the catalytic dewaxing process developed in the Delphi programming environment.

The expert system for diagnosing the causes of deviations in the operation of the industrial catalytic dewaxing unit consists of the simplified diagram of the main parts of the unit, the database containing basic information about deviations and their causes, as well as the algorithm of actions for personnel in case of the deviation occurrence.

The main program involves the following modules:

- loading of the initial data from the database;

1) List of symbols at the end of the paper.
- recalculation of the feedstock fraction composition in the group composition;

- calculation of the reactions' kinetic parameters depending on the process temperature and catalyst activity;

- mathematical model of the catalytic dewaxing process;

- algorithm for solving the system of the mathematical model equations by the Euler method;

- calculation of the cold flow properties of the produced diesel fuel;

- optimization calculation;

- downloading of the calculation results.

Fig. 4 demonstrates the algorithm for using the developed computer modeling system of the catalytic dewaxing process.

The mathematical model, which is put in the basis of the developed computer modeling system, in the event of deviation in the industrial unit operation, after issuing recommendations for its elimination, provides quantitative determination how much it is necessary to change the technological parameters (temperature, pressure, feedstock flow rate, hydrogen-containing gas consumption), so that they are optimal for obtaining the product with the required cold filter plugging point, taking into account the current feedstock composition and the catalyst activity. The developed computer modeling system can also be used as the simulator for training the industrial plant personnel in the event of deviation and for intelligent production management.

\section{Results and Discussion}

Using the developed computer modeling system, the influence of the feedstock composition and flow rate, the catalyst activity on the cold filter plugging point, and the yield of the produced diesel fuel was studied.

\subsection{Influence of the Feedstock Composition and Flow Rate on the Catalytic Dewaxing Process}

Tab. 4 presents the compositions and properties of the feedstock used for calculations.

Technological parameters of the process used in the calculations are as follows: the hydrogen-containing gas consumption is $25000 \mathrm{~m}^{3} \mathrm{~h}^{-1}$; the pressure in the reactor is $7.5 \mathrm{MPa}$; the temperature of hydrogen-containing gas is equal to $75^{\circ} \mathrm{C}$, and the feedstock flow rate varies in the range of $280-320 \mathrm{~m}^{3} \mathrm{~h}^{-1}$. 
Computer modeling system of the diesel fuel catalytic dewaxing process

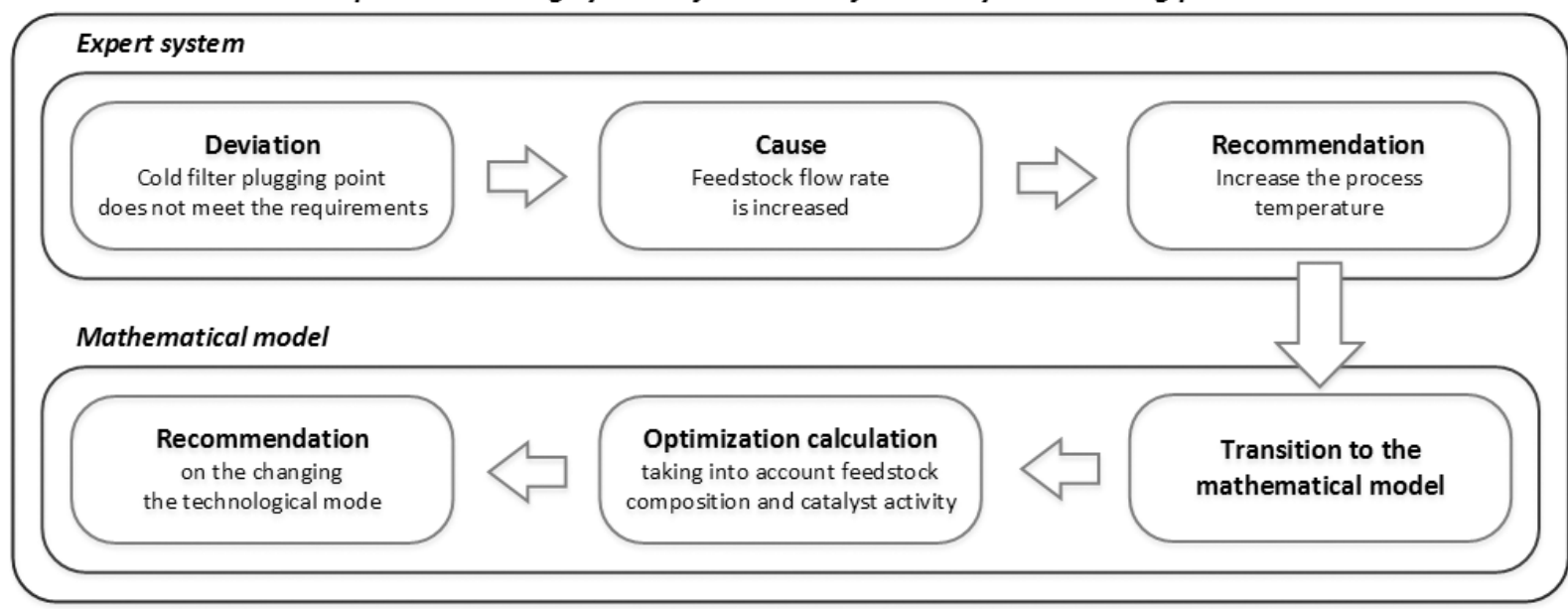

Figure 4. Algorithm for using the computer modeling system of the catalytic dewaxing process.

Table 4. Compositions and properties of the catalytic dewaxing feedstock.

\begin{tabular}{lll}
\hline & \multicolumn{2}{l}{ Distillation temperature $\left[{ }^{\circ} \mathrm{C}\right]$} \\
\cline { 2 - 3 } & Feedstock-1 & Feedstock-2 \\
\hline 10-vol \% fraction & 244 & 253 \\
50 -vol \% fraction & 282 & 299 \\
90-vol \% fraction & 344 & 354 \\
Density at $20^{\circ} \mathrm{C}\left[\mathrm{kg} \mathrm{m}^{-3}\right]$ & 840 & 853 \\
$n$-Paraffins content $[\mathrm{wt} \%]$ & 18.99 & 15.81 \\
\hline
\end{tabular}

The cold filter plugging point is considered in the study as it is the most important cold flow property of diesel fuel $[22,23]$. Tab. 5 presents the calculation results of the dewaxing process optimal temperature for the production of low-freezing diesel fuel, meeting the specifications on the cold filter plugging point for arctic or severe winter climates, class 1 (cold filter plugging point is $-26^{\circ} \mathrm{C}$, max.) according to the European Standard 590:2009 "Automotive Fuels - Diesel - Requirements and Test Methods”.
Thus, depending on the feedstock composition and flow rate, the optimal temperature for the production of low-freezing diesel fuel varies from 335 to $369^{\circ} \mathrm{C}$.

\subsection{Influence of Catalyst Activity on the Catalytic Dewaxing Process}

During the cycle between the loading of the fresh catalyst and the unloading of the deactivated catalyst, the coke content gradually increases, due to which the activity of the catalyst gradually decreases. The accumulated coke content is calculated by solving the system of differential equations (Eq. (1)) in a cycle. The activity of the catalyst is calculated using Eq. (2), taking into account the increase in the coke content on the catalyst due to its accumulation as the cycle proceeds.

The calculation was carried out for different activities of the catalyst from 1.0 to 0.7 relative units at the same technological parameters given in Tab.5 (the feedstock composition is Feedstock-1, Tab.4) and varying flow rate in the range of 280-320 $\mathrm{m}^{3} \mathrm{~h}^{-1}$ (Tab. 6).

Thus, with a decrease in the catalyst activity by $30 \%$, the optimum process temperature for the production of low-freezing diesel fuel varies from 363 to $376^{\circ} \mathrm{C}$.

Table 5. Optimal process temperature at the varying feedstock composition and flow rate.

\begin{tabular}{|c|c|c|c|c|c|c|}
\hline Parameter & Value & & & & & \\
\hline Cold filter plugging point $\left[{ }^{\circ} \mathrm{C}\right]$ & -26 & & & & & \\
\hline Catalyst activity [-] & 1.0 & & & & & \\
\hline Feedstock flow rate $\left[\mathrm{m}^{3} \mathrm{~h}^{-1}\right]$ & 280 & & 300 & & 320 & \\
\hline Feedstock & 1 & 2 & 1 & 2 & 1 & 2 \\
\hline Optimal process temperature $\left[{ }^{\circ} \mathrm{C}\right]$ & 363 & 335 & 366 & 338 & 369 & 341 \\
\hline Diesel fuel yield [\%] & 86.0 & 86.0 & 85.8 & 85.7 & 85.5 & 85.5 \\
\hline
\end{tabular}


Table 6. Optimal process temperature at the varying catalyst activity.

\begin{tabular}{|c|c|c|c|c|c|c|}
\hline Parameter & Value & & & & & \\
\hline Cold filter plugging point $\left[{ }^{\circ} \mathrm{C}\right]$ & -26 & & & & & \\
\hline$n$-Paraffins content in the feedstock [wt \%] & 18.99 & & & & & \\
\hline Feedstock flow rate $\left[\mathrm{m}^{3} \mathrm{~h}^{-1}\right]$ & 280 & & 300 & & 320 & \\
\hline Catalyst activity [-] & 1.0 & 0.7 & 1.0 & 0.7 & 1.0 & 0.7 \\
\hline Optimal process temperature $\left[{ }^{\circ} \mathrm{C}\right]$ & 363 & 370 & 366 & 373 & 369 & 376 \\
\hline Diesel fuel yield [\%] & 86.0 & 85.8 & 85.8 & 85.7 & 85.5 & 85.4 \\
\hline
\end{tabular}

\section{Conclusions}

The developed computer modeling system of the diesel fuel catalytic dewaxing process is based on the unsteady physicochemical mathematical model of the process. It is sensitive to the composition of the processed feedstock and the catalyst activity. This provides applying the system at the catalytic dewaxing industrial plants and in case of deviations in operation to recommend the optimal technological mode in order to produce low-freezing diesel fuel with the required cold filter plugging point. The developed computer modeling system can also be used as the simulator for training industrial plant personnel in the event of deviation in the unit operation and for intelligent production management.

\section{Acknowledgment}

This research is supported by the Tomsk Polytechnic University within the framework of Tomsk Polytechnic University Competitiveness Enhancement Program and Russian State Project "Science" No. FSWW-2020-0011.

The authors have declared no conflict of interest.

\section{Symbols used}

$\begin{array}{ll}a_{\mathrm{j}} & {[-]} \\ A_{\mathrm{j}} & {[-]} \\ & \\ C_{\mathrm{i}} & {\left[\mathrm{mol} \mathrm{L}^{-1}\right]} \\ C_{\mathrm{K}} & {\left[\mathrm{wt} \%{ }{ }^{-1}\right.} \\ C_{\mathrm{p}}{ }^{\text {mix }} & {\left[\mathrm{J} \mathrm{kg}^{-1} \mathrm{~K}^{-1}\right]} \\ G & {\left[\mathrm{~m}^{3} \mathrm{~h}^{-1}\right]} \\ m & {[-]} \\ Q_{\mathrm{j}} & {\left[\mathrm{J} \mathrm{mol}^{-1}\right]} \\ T & {[\mathrm{~K}]} \\ t & {[\mathrm{~h}]} \\ & \\ V & {\left[\mathrm{~m}^{3}\right]} \\ W_{\mathrm{j}} & {\left[\mathrm{mol} \mathrm{L}^{-1} \mathrm{~s}^{-1}\right]} \\ z & {\left[\mathrm{~m}^{3}\right]}\end{array}$

catalyst activity in $j$ th reaction deactivation coefficient for $j$ th reaction content of $i$ th component content of coke specific heat capacity of the mixture feedstock flow rate number of reactions heat effect of $j$ th reaction temperature catalyst operating time from the moment of fresh catalyst load catalyst bed volume rate of $j$ th reaction volume of refined feedstock from the moment of fresh catalyst load
Greek letters

$\begin{array}{lll}\alpha_{\mathrm{j}} & {[-]} & \begin{array}{l}\text { deactivation coefficient for } j \text { th } \\ \text { reaction } \\ \text { density of mixture }\end{array} \\ \rho & {\left[\mathrm{kg} \mathrm{m}^{-3}\right]} & \end{array}$

Sub- and superscripts

$i \quad$ index of the component

$j \quad$ index of the reaction

\section{Abbreviations}

C-1 stabilization column

C-2 fractionating column

$\mathrm{R}-1, \mathrm{R}-2$ hydrotreating reactors

R-3 dewaxing reactor

S-1 high-pressure separator

S-2 low-pressure separator

S-4 reflux tank

T-5 reflux tank

\section{References}

[1] K. H. Kang, G. T. Kim, S. Park, P. V. Seo, H. Seo, C. W. Lee, Ind. Eng. Chem. 2019, 76, 1-16. DOI: https://doi.org/ 10.1016/j.jiec.2019.03.022

[2] A. Marafi, H. Albazzaz, M. S. Rana, Catal. Today 2019, 329, 125-134. DOI: https://doi.org/10.1016/j.cattod.2018.10.067

[3] A. I. Grudanova, L. A. Gulyaeva, L. A. Krasilnikova, O. I. Shmelkova, R. E. Boldushevskii, Fuel 2017, 193, 485-487. DOI: https://doi.org/10.1016/j.fuel.2016.12.032

[4] I. Rossetti, C. Gamboro, V. Calemma, Chem. Eng. J. 2009, 154 (1-3), 295-301. DOI: https://doi.org/10.1016/ j.cej.2009.03.018

[5] M. Afenyo, C. Jianga, A. Ng, Transp. Res. Part D 2019, 77, 476-490. DOI: https://doi.org/10.1016/j.trd.2019.05.009

[6] S. W. Lee, S. K. Ihma, Fuel 2014, 134, 237-243. DOI: https:// doi.org/10.1016/j.fuel.2014.05.068

[7] C. J. Calderón, J. Ancheyta, Fuel 2019, 244, 258-268. DOI: https://doi.org/10.1016/j.fuel.2019.01.138

[8] E. D. Ivanchina, E. N. Ivashkina, I. O. Dolganova, N. S. Belinskaya, Rev. Chem. Eng., in press. DOI: https://doi.org/ 10.1515/revce-2018-0038 
[9] A. N. Zagoruiko, A. S. Belyi, M. D. Smolikov, A. S. Noskov, Catal. Today 2014, 220-222, 168-177. DOI: https://doi.org/ 10.1016/j.cattod.2013.07.016

[10] A. G. Frank, L. S. Dalenogare, N. F. Ayala, Int. J. Prod. Econ. 2019, 210, 15-26. DOI: https://doi.org/10.1016/ j.ijpe.2019.01.004

[11] E. D. Ivanchina, M. V. Kirgina, N. V. Chekantsev, B. V. Sakhnevich, E. V. Sviridova, R. V. Romanovskiy, Chem. Eng. J. 2015, 282, 194-205. DOI: https://doi.org/10.1016/ j.cej.2015.03.014

[12] E. Ketabchi, E. Mechleri, S. Gu, H. Arellano-Garcia, Comput. Chem. Eng. 2017, 105, 105-122. DOI: https://doi.org/ 10.1016/B978-0-444-64241-7.50175-0

[13] L. F. L. Moro, A. C. Zanin, J. M. Pinto, Comput. Chem. Eng. 1998, 22 (1), 1039-1042. DOI: https://doi.org/10.1016/ S0098-1354(98)00209-9

[14] E. S. Perez-Cisneros, M. Sales-Cruz, R. Lobo-Oehmichen, T. Viveros-García, Comput. Chem. Eng. 2017, 105, 105-122. DOI: https://doi.org/10.1016/j.compchemeng.2017.01.018

[15] V. Mittal, T. Cai, K. Krishnadevarajan, Q. Xu, Chem. Eng. Technol. 2014, 37 (2), 293-300. DOI: https://doi.org/ $10.1002 /$ ceat.201300267
[16] E. Aydin, A. D. Celebi, H. Sildir, Y. Arkun, U. Canan, G. Is, M. Erdogan, Comput. Chem. Eng. 2015, 82, 44-54. DOI: https://doi.org/10.1016/j.compchemeng.2015.06.005

[17] E. Aydin, Y. Arkun, G. Is, M. Mutlu, M. Dikbas, Comput. Chem. Eng. 2016, 87, 234-245. DOI: https://doi.org/10.1016/ j.compchemeng.2016.01.016

[18] B. Khadem-Hamedani, S. Yaghmaei, M. Fattahi, S. Mashayekhan, S. Hosseini-Ardali, Chem. Eng. Res. Des. 2015, 100, 362-376. DOI: https://doi.org/10.1016/j.cherd.2015.05.023

[19] L. de R. Novares, N. S. de Resende, V. M. M. Salim, A. R. Secchi, Fuel 2017, 209, 184-193. DOI: https://doi.org/ 10.1016/j.fuel.2017.07.092

[20] H. Zhou, J. Lu, Z. Cao, J. Shi, M. Pan, W. Li, Q. Jiang, Fuel 2011, 90 (12), 3521-3530. DOI: https://doi.org/10.1016/ j.fuel.2011.02.043

[21] N. S. Belinskaya, E. V. Frantsina, E. D. Ivanchina, Chem. Eng. J. 2017, 329, 283-294. DOI: https://doi.org/10.1016/ j.cej.2017.04.033

[22] C. Zschiesche, D. Himsl, R. Rakoczy, A. Reitzmann, J. Freiding, N. Wilde, R. Gläser, Chem. Eng. Technol. 2018, 41 (1), 199-204. DOI: https://doi.org/10.1002/ceat.201700236

[23] A. Vráblík, R. Velvarská, K. Štěpánek, M. Pšenička, J. Miguel, H. Radek Černý, Chem. Eng. Technol. 2019, 42 (4), 735-743. DOI: https://doi.org/10.1002/ceat.201800549 